\title{
Economic evaluations of peritoneal dialysis and hemodialysis:
}

\section{4-2012 [version 1; peer review: 1 approved, 1 approved}

\section{with reservations]}

\author{
Frank Xiaoqing Liu' ${ }^{1}$, Tiffany P. Quock², John Burkart ${ }^{3,4}$, Les L. Noe ${ }^{5}$, Gary Inglese ${ }^{6}$
}

${ }^{1}$ Baxter Healthcare Corporation, Deerfield, IL 60015, USA

${ }^{2}$ Covance Market Access Services Inc, San Diego, CA 92121-1511, USA

3 Wake Forest University, Winston-Salem, NC 27157, USA

${ }^{4}$ Health System Management, Tifton, GA 31794, USA

5InVentiv Health Clinical, Deerfield, IL 80301, USA

${ }^{6}$ Hollister Incorporated, Libertyville, IL 60048, USA

\section{V1 First published: $16 \operatorname{Dec} 2013,2: 273$ \\ https://doi.org/10.12688/f1000research.2-273.v1}

Latest published: 16 Dec 2013, 2:273

https://doi.org/10.12688/f1000research.2-273.v1

\section{Abstract}

Background: End-stage renal disease (ESRD) is a debilitating condition resulting in death unless treated. Treatment options include conservative care, transplantation, and dialysis. Major alternative dialysis modalities include peritoneal dialysis (PD) and in-center hemodialysis (ICHD), which have been shown to produce similar outcomes and survival. The need to provide dialysis treatment for patients with ESRD represents a significant financial challenge for global health care systems. Changes in clinically-appropriate dialysis delivery leading to more efficient use of resources would increase health systems' ability to meet that challenge. The purpose of this paper is to evaluate the economic literature of PD and ICHD within the context of continued economic uncertainty and pressure on healthcare resource use.

Methods: A systematic literature search was conducted for studies published between 2004 and 2012. Articles are included if they were original research studies in English which reported costs and/or cost effectiveness associated with PD and ICHD.

Results: Twenty-four articles are included in our review, six of which are cost effectiveness studies comparing PD and ICHD.

Conclusions: Our findings echo those of prior published reviews, showing that PD is significantly cost-saving compared to ICHD therapy in most developed countries and some developing countries. Increasing the use of clinically-appropriate PD would substantially reduce healthcare costs.

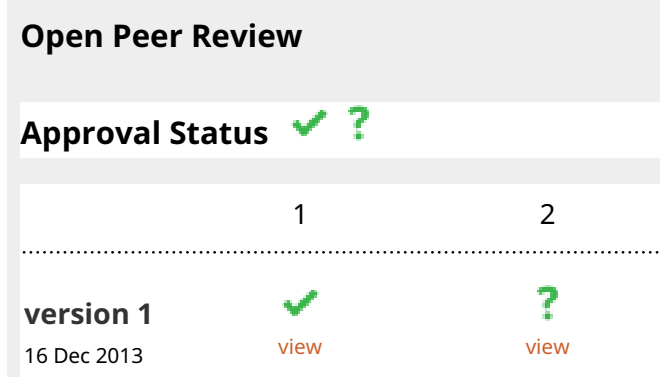

1. Scott Klarenbach, University of Alberta, Alberta, Canada

2. Allen R. Nissenson, DaVita Inc., El Segundo, CA, USA

Any reports and responses or comments on the article can be found at the end of the article. 
Corresponding author: Frank Xiaoqing Liu (xiaoqing_liu@baxter.com)

Competing interests: Frank Xiaoqing Liu is an employee and stockholder of Baxter Healthcare Corporation, Deerfield, IL USA; At the time this research was conducted, Tiffany Quock and Les Noe were employees of ICON, which received research funding from Baxter Healthcare Corporation for the systematic review. Tiffany is now at Covance Market Access Services Inc. and Les is now at InVentiv Health Clinical; John Burkart is faculty at Wake Forest University, Winston-Salem, NC, USA and has been an ad hoc consultant for Baxter Healthcare Corporation; Gary Inglese was an employee of Baxter Healthcare Corporation at the time of this manuscript development and is now at Hollister Incorporated.

Grant information: The study was supported by funding from Baxter Healthcare Corporation, Deerfield, IL 60015 USA. The publication of the study results was not contingent on the sponsor's approval or censorship of the manuscript.

The funders had no role in study design, data collection and analysis, decision to publish, or preparation of the manuscript.

Copyright: $\odot 2013$ Liu FX et al. This is an open access article distributed under the terms of the Creative Commons Attribution License, which permits unrestricted use, distribution, and reproduction in any medium, provided the original work is properly cited. Data associated with the article are available under the terms of the Creative Commons Zero "No rights reserved" data waiver (CC0 1.0 Public domain dedication).

How to cite this article: Liu FX, Quock TP, Burkart J et al. Economic evaluations of peritoneal dialysis and hemodialysis: $2004-2012$ [version 1; peer review: 1 approved, 1 approved with reservations] F1000Research 2013, 2:273

https://doi.org/10.12688/f1000research.2-273.v1

First published: 16 Dec 2013, 2:273 https://doi.org/10.12688/f1000research.2-273.v1 


\section{Introduction}

End-stage renal disease (ESRD) is a debilitating condition resulting in death unless treated. Kidney transplantation, dialysis, and conservative therapy supported by palliative care are the three primary treatment options for patients with ESRD ${ }^{1,2}$. Although kidney transplantation is the most cost-effective therapy, the supply of donor kidneys is limited ${ }^{3}$. In addition, patients who are eligible for and choose kidney transplantation usually have to wait months to years for a kidney to become available. During this waiting period, patients are treated with dialysis. The two main types of dialysis are hemodialysis (HD) and peritoneal dialysis (PD). In HD, the removal of wastes and excess fluid is accomplished by circulating blood outside the body through an external filter (dialyzer). HD is usually performed in a hospital or clinic (in-center HD or ICHD), but can also be performed at home (HHD). Conventional HD is typically performed three times per week, with each treatment lasting 3 to 5 hours. In PD, the removal of wastes and excess fluid is accomplished inside the body, in the abdominal or peritoneal cavity. A dialysis solution is placed in the peritoneal cavity, which allows wastes to move from the blood to this solution. After a period of time, the solutions are drained from the body ${ }^{4}$. Unlike HD ${ }^{5}, \mathrm{PD}$ is usually a continuous therapy, in which dialysis solutions are repeatedly drained from and instilled into the peritoneal cavity so there is a possibility of dialysate dwell (and hence solute removal) up to 24 hours/day 7 days a week ${ }^{4}$. However, some patients are treated with intermittent PD, which is either performed manually (the patient uses gravity to fill and drain the abdominal cavity) through continuous ambulatory PD (CAPD) treatment, or with a cycler (a machine that automatically fills and drains the abdominal cavity, usually while the patient sleeps), in automated PD (APD) treatment ${ }^{6}$.

The prevalence of ESRD (estimated to be 2.8 million globally at the end of $2011^{7}$ ) and, consequently, the demand for dialysis, continues to increase due to an aging population, extended life expectancies, the increased prevalence of precipitating conditions such as diabetes ${ }^{6}$. Worldwide, hemodialysis continues to be the most common mode of therapy for individuals with $\mathrm{ESRD}^{6}$ and the need to provide dialysis treatments for a large and growing patient population places a heavy economic burden on the global health care system ${ }^{8}$. In the United States, (US), for example, $1.3 \%$ of Medicare patients with ESRD accounted for $7.5 \%$ of Medicare spending in $2010^{5}$.

In response to such pressures, initiatives aimed specifically at controlling dialysis-related costs have already been implemented in many countries, including Australia, Portugal, Thailand, United Kingdom (UK) and US ${ }^{9-14}$. For example, the Australian government implemented a range of national health reforms in 2012, including a national efficient price (NEP) for hospital services, which was based on the average costs of best practice pathways ${ }^{14}$. Similarly, Portugal implemented a bundled payment program for dialysis, bundling dialysis services and products into one rate ${ }^{11}$. In addition, the Centers for Medicare and Medicaid Services (CMS) in the US enacted an expanded bundled prospective payment system (PPS) for dialysis services in order to control for the unpredictable and escalating costs associated with the provision of dialysis, and to combine pharmaceuticals and lab services that were previously charged separately ${ }^{13}$. These and other initiatives are similar in striving for maintaining healthcare costs and identifying interventions that are less resource intensive and/or cost-effective. Given this changing economic environment, where payers and providers around the world are facing pressure to control healthcare costs while improving patient outcomes, we conducted a systematic review of economic evaluations of PD and ICHD published since 2004. Our purpose was to assess whether the recent literature continues to support the use of PD to be a less resource intensive therapy compared with HD from payer, provider and societal perspectives ${ }^{15}$.

\section{Methods}

We conducted a systematic literature search for peer-reviewed economic evaluations of dialysis modalities published between January 1, 2004 and March 31, 2012 in the second quarter of 2012. To ensure that we captured articles that might not have been included in the database for the prior literature synthesis which assessed literature from 1996-2006, our literature search included an overlap of three years of inclusion (2004-2012) with the prior literature synthesis. We applied our search strategies in PubMed; EMBASE; Cochrane Collaboration; Database of Abstracts of Reviews of Effects; UK National Health System Economic Evaluations Database; and Health Technology Assessment Database. Medicine indexing terms for dialysis therapies, including renal replacement therapy, peritoneal dialysis, renal dialysis, and hemodialysis units, hospital that linked to the subheading economics, and free-text search terms, including hemodialysis, peritoneal dialysis, renal dialysis, continuous ambulatory peritoneal dialysis, conventional hemodialysis, automated peritoneal dialysis, cost, costs, expenditures, cost analysis, cost effectiveness, cost benefit analysis, pharmacoeconomics, health economics, and economics, were used in the database search.

Our search identified 498 publications (Figure 1). Two investigators (FXL and TPQ) screened $40 \%$ of all the found abstracts

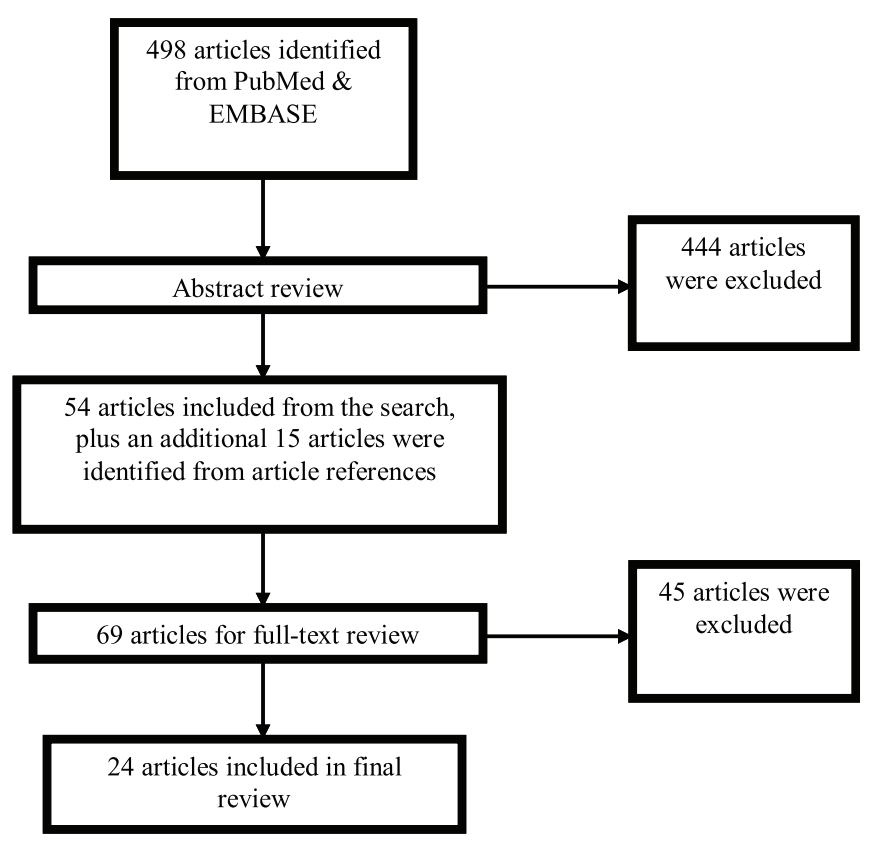

Figure 1. Flow chart of study selection. 
independently based on our research objective. With $96 \%$ of the selected articles matched, one investigator (TPQ) continued the remaining selection. Articles were excluded $(n=444)$ if they were of the following publication types: Editorial, Letter, Case Report, Comment, Interview, Lecture, News, Newspaper Article, or Patient Education Handout, or if the title/abstract did not suggest that a comparison was made between the costs of at least one sub-modality of PD to at least one sub-modality of ICHD. Articles were included $(n=54)$ if they were original research studies with text in English, and if they compared costs and/or cost effectiveness associated with PD and ICHD or subtypes of PD and ICHD. To be comprehensive, additional articles $(n=15)$ were identified through a review of references from the selected papers. These 69 articles were subjected to full-text review and further inclusion criteria were applied. Studies that did not focus on an economic evaluation of dialysis, or did not differentiate between the costs of PD and ICHD (or their subtypes) were excluded, as were review articles with no original data. Twenty-four articles (18 cost studies and 6 cost-effectiveness studies) met all of these inclusion criteria. Relevant study data were manually extracted (TPQ) and cross-checked for accuracy (FXL).

\section{Results}

The 24 articles included in our review provide economic and costutility data from 13 high-income (Australia, Austria, Finland, France, Greece, Italy, Japan, New Zealand, Singapore, Spain, Switzerland, UK, US), three upper-middle income (Chile, Malaysia, Mexico), and six lower-middle income (China, Columbia, India, Romania, Thailand, Turkey) countries. Designations of high, upper-middle, and lower-middle income countries are based on World Bank definitions whereby economies are divided according to the 2011 gross national income (GNI) per capita, which is calculated using the World Bank Atlas method. Defined groups are: low income, $\$ 1,025$ or less; lower-middle income, $\$ 1,026-\$ 4,035$; upper-middle income, $\$ 4,036-\$ 12,475$; and high income, $\$ 12,476$ or more ${ }^{16}$. Table 1 outlines the costs of ICHD and PD found in 19 countries from our 18 cost studies.

Cross-country comparisons of economic data are challenging to perform well under the best of circumstances, but perhaps especially in the case of dialysis, where ICHD-related costs are comprised primarily of labor and capital expenses, whereas PD-related costs are associated primarily with disposables, such as dialysate solutions and supplies. In this review, the usual concerns were compounded by the variability of the data compared within individual studies and by incomplete transparency within individual reports. Cost perspectives, where specified, ranged from patients, service providers, and payers to government health systems. With different perspectives, different costs are considered relevant and different methods of apportioning direct and overhead expenses may influence the reported results ${ }^{17}$. The currency years reported in these studies, where specified, spanned more than a decade (1997 to 2010), demanding significant assumptions to adjust for price inflation, international currency valuations, and purchasing power parity in order to arrive at a common-currency metric. Furthermore, differences in provider payment and healthcare financing systems, variation in rates of HD versus PD use affecting economies of scale across different countries, and potential differences in treatment settings intensify the challenges for cross-country comparisons of these studies. Data sources were similarly varied, including literature-derived secondary sources, hospital records, insurance information, disease registries, government publications, expert opinions, surveys, and semi-structured interviews. Finally, the 19 countries from which dialysis costs were reported are at different levels of economic development. As such, they have widely varying infrastructures available to support dialysis services, as well as different barriers to the use of each dialysis modality ${ }^{18,19}$. Each of these factors further magnify the danger of cross-country comparisons ${ }^{20}$. Nevertheless, the data shown in Table 1 remain valuable insofar as they highlight the magnitude of dialysis costs and the relative (not absolute) cost differences between the dialysis modalities across countries. Ratios of costs for ICHD compared to PD are included in Table 1 to assist with this exercise. Ratios less than 1.00 (parity) denote lower cost of ICHD compared to PD.

The findings from our review demonstrate that ICHD costs, whether they are medical direct-, total medical-, or total medical plus indirect costs, are generally (but not always) higher than PD costs. A 2009 Finnish study ${ }^{21}$ of the total medical costs (payer perspective) of PD and ICHD reported that the cost of ICHD tended to be about $25 \%-38 \%$ higher than the cost of PD (ICHD:PD ratio $=1.25-1.38$ ). In contrast, a 2007 study evaluating the direct costs of PD and ICHD (payer perspective) in Japan ${ }^{22}$, found that the cost of ICHD tended to be about $86 \%$ of the cost of PD (ICHD:PD ratio $=0.86$ ). Nevertheless, data from $82 \%(9 / 11)$ of the high-income, $50 \%(1 / 2)$ of the upper-middle income, and $83 \%(5 / 6)$ of the lower-middle income countries represented in our review show the cost of ICHD to be more than that of PD. Figure 2 arrays the country-specific cost ratios for ICHD compared to $\mathrm{PD}$.

Six of the 24 studies in our review were cost-effectiveness or costutility studies; that is, they considered the outcomes of each dialysis modality in terms of patient life-years, and/or healthy life-years (typically measured as quality-adjusted life years) in addition to costs. Despite wide variability in methodologies, outcome measures, perspectives, time horizons, costs, and analytic approaches used in these six studies, each came to a similar conclusion: the cost-effectiveness of PD is equivalent to (1 study), or better than ( 5 studies) the cost-effectiveness of ICHD (Table 2).

The 24 economic analyses reviewed in the context of this study were of variable quality. This is a particular concern because the individuals who need to use these analyses to guide decisions may not be experts at evaluating them ${ }^{23}$. To document the quality differences between studies in the context of this review, we characterized the reports using criteria adapted from the Quality of Health Economics Studies (QHES) instrument ${ }^{23}$, which was specifically developed to emphasize appropriate methods; and valid, transparent, and comprehensive results reporting in health economic analyse ${ }^{23}$.

Characteristics of high-quality studies not only clearly specified the objective, perspective, and data source, but also included a detailed description of the study methodologies; total direct, non-direct, indirect, and intangible medical costs; and addressed both limitations and biases. While the majority of cost-effectiveness studies clearly described study objective, perspective, and study estimates $(83 \%-100 \%)$, fewer studies addressed the validity of outcome measures 
Table 1. Annual cost of ICHD and PD in 19 countries.

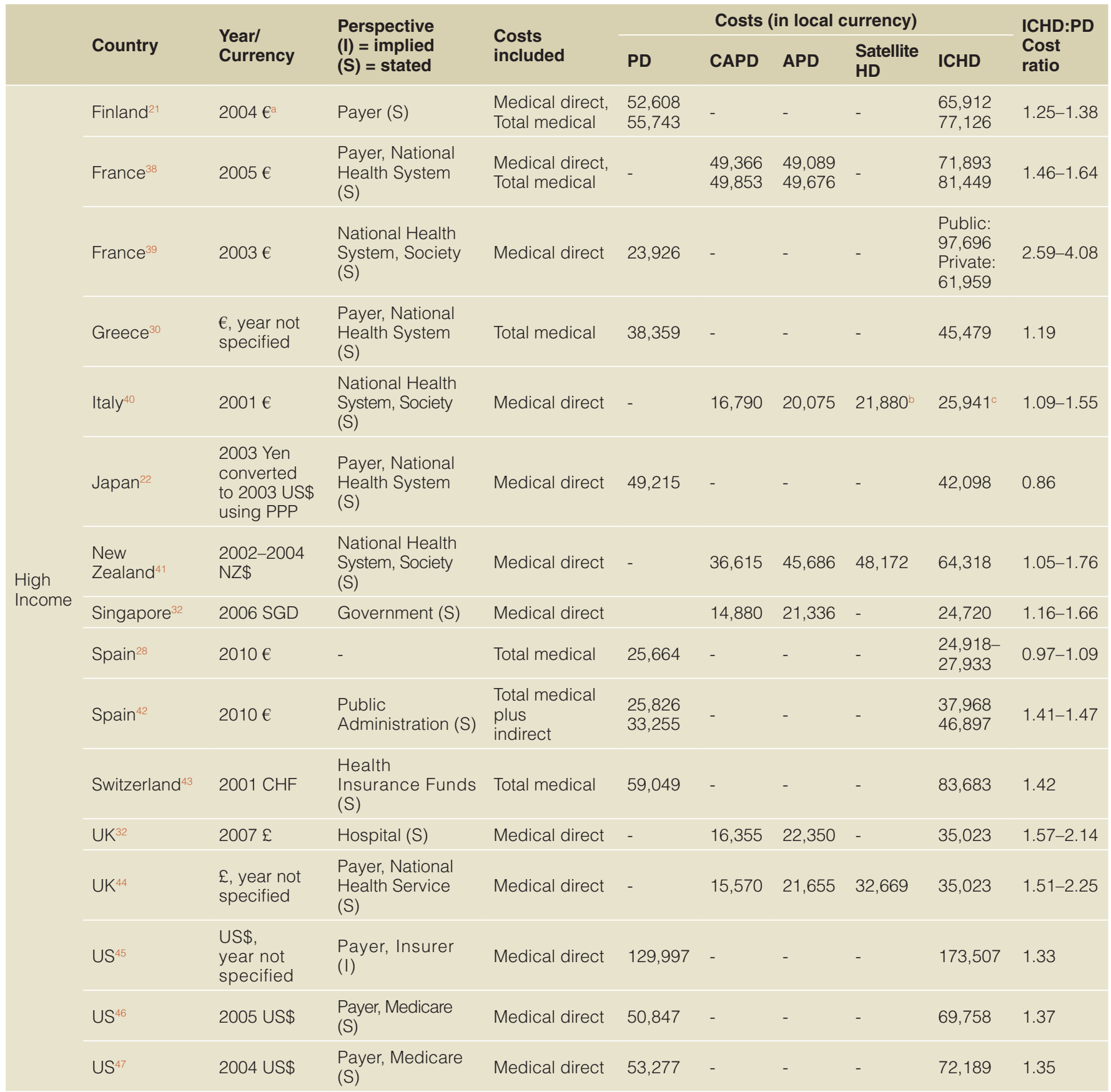




\begin{tabular}{|c|c|c|c|c|c|c|c|c|c|c|}
\hline & \multirow[b]{2}{*}{ Country } & \multirow{2}{*}{$\begin{array}{l}\text { Year/ } \\
\text { Currency }\end{array}$} & \multirow{2}{*}{$\begin{array}{l}\text { Perspective } \\
(I)=\text { implied } \\
(S)=\text { stated }\end{array}$} & \multirow{2}{*}{$\begin{array}{l}\text { Costs } \\
\text { included }\end{array}$} & \multicolumn{5}{|c|}{ Costs (in local currency) } & \multirow{2}{*}{$\begin{array}{l}\text { ICHD:PD } \\
\text { Cost } \\
\text { ratio }\end{array}$} \\
\hline & & & & & PD & CAPD & APD & $\begin{array}{l}\text { Satellite } \\
\text { HD }\end{array}$ & ICHD & \\
\hline \multirow{3}{*}{$\begin{array}{l}\text { Upper- } \\
\text { Middle } \\
\text { Income }\end{array}$} & Chile $^{32}$ & 2005 US\$ & Government (I) & Total medical & 17,031 & - & - & - & 18,885 & 1.12 \\
\hline & Chile $^{33}$ & 2005 US\$ & Payer, Society (I) & $\begin{array}{l}\text { Medical direct, } \\
\text { Total medical } \\
\text { plus indirect }\end{array}$ & $\begin{array}{l}16,666 \\
20,742\end{array}$ & - & - & - & $\begin{array}{l}14,884 \\
20,803\end{array}$ & $0.89-1.00$ \\
\hline & Mexico $^{32}$ & 2006 US\$ & $\begin{array}{l}\text { Government } \\
\text { (S) }\end{array}$ & Medical direct & 15,724 & - & - & - & 24,032 & 1.53 \\
\hline \multirow{6}{*}{$\begin{array}{l}\text { Lower- } \\
\text { Middle } \\
\text { Income }\end{array}$} & China $^{32}$ & $2005 \mathrm{RMB}$ & Hospital (S) & Total medical & 84,141 & - & - & - & 98,204 & 1.17 \\
\hline & Columbia ${ }^{32}$ & 2005 US\$ & $\begin{array}{l}\text { Government } \\
\text { (I) }\end{array}$ & $\begin{array}{l}\text { Hospitalization } \\
\text { costs only }\end{array}$ & - & 775 & 884 & - & 2,144 & $2.43-2.77$ \\
\hline & India ${ }^{48}$ & $\begin{array}{l}2010 \\
\text { Rupees }\end{array}$ & Patients (I) & $\begin{array}{l}\text { Medical direct, } \\
\text { Total medical }\end{array}$ & $\begin{array}{l}19,528 \\
28,763\end{array}$ & - & - & - & $\begin{array}{l}14,669 \\
29,252\end{array}$ & $0.75-1.02$ \\
\hline & Romania $^{32}$ & $2006 €$ & $\begin{array}{l}\text { Government } \\
\text { (S) }\end{array}$ & Medical direct & 12,700 & - & - & - & 18,400 & 1.45 \\
\hline & Thailand $^{32}$ & 2005 Baht & $\begin{array}{l}\text { Government } \\
\text { (I) }\end{array}$ & Total medical & 461,541 & - & - & - & 519,047 & 1.12 \\
\hline & Turkey $^{49}$ & 2001 US\$ & $\begin{array}{l}\text { Payer, Various } \\
\text { (I) }\end{array}$ & Medical direct & - & 22,350 & - & - & 22,759 & 1.02 \\
\hline
\end{tabular}

Note: medical direct costs (dialysis, laboratory, and other directly related costs); total medical (medical direct and non-medical spending, including transportation) costs; total medical costs plus indirect treatment costs (such as loss of productivity); "“- not available

Based on World Bank definitions for classifying economies: low income, $\$ 1,205$ or less; lower-middle income, $\$ 1,026$ - $\$ 4,035$; upper-middle income, $\$ 4,036-\$ 12,475$; and high income, $\$ 12,476$ or more

amall sample size of 29 patients and is insufficient to assess costs

${ }^{\mathrm{b}}$ For Satellite HD: weighted calculation $=\left(129^{*} 52^{*} 3^{*} 0.83+207^{*} 52^{*} 3^{*} 0.14\right) / 0.97$

${ }^{\circ}$ For Hospital HD: weighted calculation $=\left(155^{\star} 52^{\star} 3^{\star} 0.83+232^{\star} 52^{*} 3^{*} 0.14+258^{\star} 52^{*} 3^{*} 0.02\right)$

§PD: peritoneal dialysis; HD: hemodialysis; ICHD: in-center hemodialysis; CAPD: continuous ambulatory peritoneal dialysis; APD: automated peritoneal dialysis; cost ratios are calculated by dividing highest value with lowest value

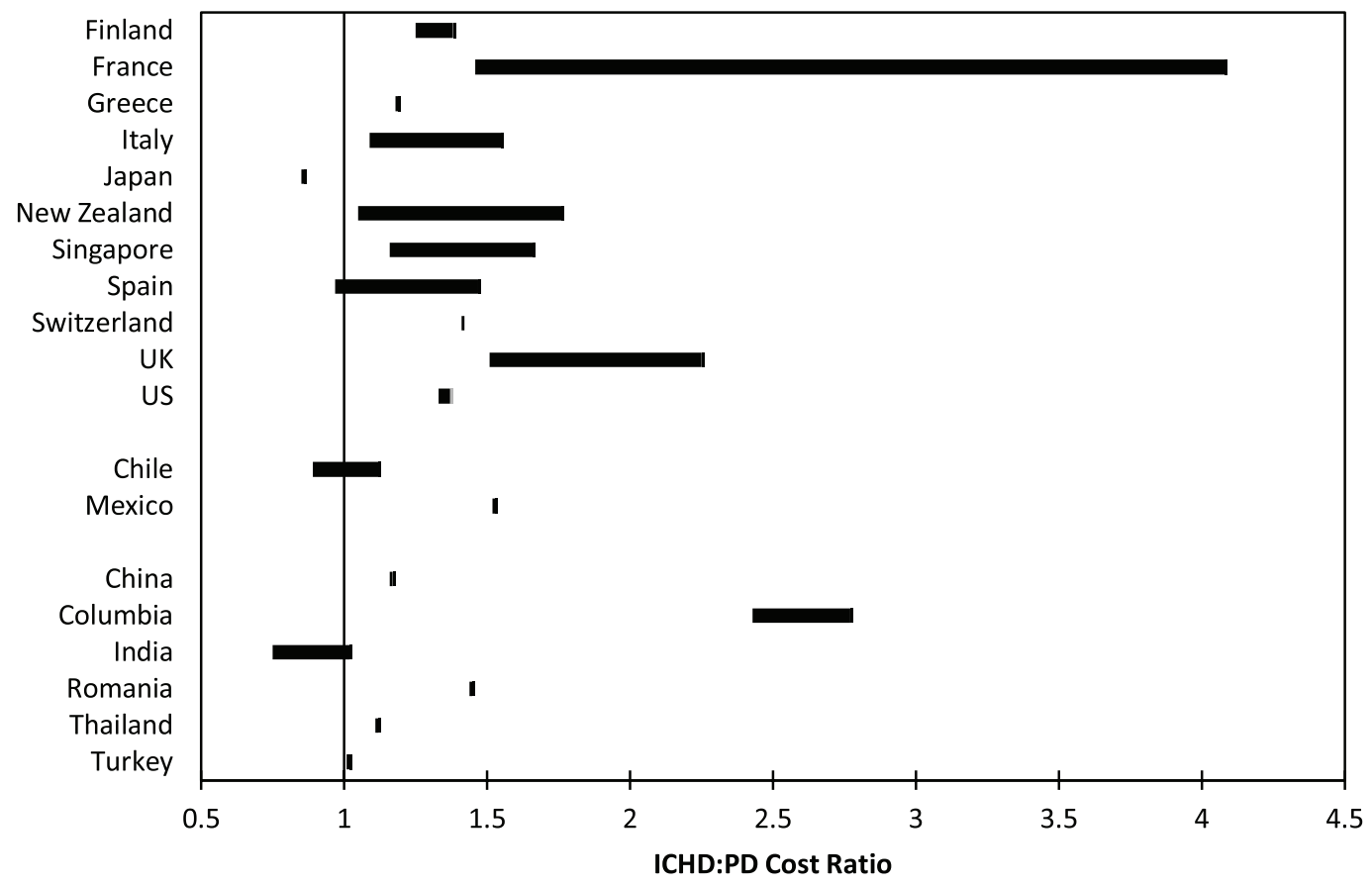

Figure 2. PD (peritoneal dialysis): ICHD (in-center hemodialysis) cost ratios in 19 countries. 
Table 2. Cost-effectiveness/cost-utility of ICHD and PD.

\begin{tabular}{|c|c|c|c|}
\hline Country & $\begin{array}{l}\text { Outcome } \\
\text { measure* }\end{array}$ & Conclusion & Comments \\
\hline Australia ${ }^{35}$ & LY, QALY & $\begin{array}{l}\text { Home-based dialysis } \\
\text { options (including PD) } \\
\text { are more cost-effective } \\
\text { compared to ICHD }\end{array}$ & $\begin{array}{l}\text { Increasing rate of PD by switching patients from ICHD saves } \\
\text { A } \$ 122.1 \text { million annually (central health-care payer perspective). The } \\
\text { reported model lacked good quality data on changes in utility-based } \\
\text { quality of life resulting in changes to dialysis modality; however, the } \\
\text { authors conclude that it is reasonable to assume improved quality of } \\
\text { life with PD (vs. ICHD) }\end{array}$ \\
\hline Austria $^{34}$ & QALY & $\begin{array}{l}\text { PD is more cost-effective } \\
\text { compared to ICHD }\end{array}$ & $\begin{array}{l}\text { Increasing assignment to PD of } 20 \% \text { incident patients saves } € 26 \\
\text { million (payer perspective) and gains } 839 \text { QALY over } 10 \text { years }\end{array}$ \\
\hline Greece $^{36}$ & QALY & $\begin{array}{l}\text { PD is more cost-effective } \\
\text { compared to ICHD }\end{array}$ & $\begin{array}{l}\text { Health system payer perspective. PD produces a lower cost per } \\
\text { QALY }(€ 54,504) \text { compared to ICHD }(€ 60,353)\end{array}$ \\
\hline Finland $^{50}$ & LY & $\begin{array}{l}\text { CAPD is more cost- } \\
\text { effective compared to } \\
\text { ICHD }\end{array}$ & $\begin{array}{l}\text { From the provider perspective, where costs represent 3-year } \\
\text { cumulative costs and effectiveness represents 3-year survival. } \\
\text { The ratio of cost-effectiveness for CAPD:ICHD ranges from .64 to } \\
.94 \text { (depending on the analysis strategy), indicating that CAPD is } \\
\text { consistently more cost-effective than ICHD }\end{array}$ \\
\hline Malaysia $^{51}$ & LY & $\begin{array}{l}\text { CAPD is marginally more } \\
\text { cost-effective compared } \\
\text { to ICHD }\end{array}$ & $\begin{array}{l}\text { Ministry of Health perspective. Cost per life-year gained is RM } \\
31,635 \text { for CAPD vs. RM 33,642 for ICHD. The authors conclude } \\
\text { that CAPD and ICHD are both viable options in Malaysia, and that } \\
\text { both modalities can be delivered efficiently (i.e., CAPD center } \\
\text { serving approximately } 100 \text { patients annually; HD center providing } \\
\text { approximately } 15,000 \text { HD treatments annually) }\end{array}$ \\
\hline Thailand $^{31}$ & LY, QALY & $\begin{array}{l}\text { PD is more cost-effective } \\
\text { compared to ICHD, } \\
\text { especially in younger } \\
\text { patients with ESRD }\end{array}$ & $\begin{array}{l}\text { In models with adjusted and unadjusted survival, the incremental } \\
\text { costs of providing 'PD first' ranged from } 466,000 \text { Baht per LY saved } \\
\text { ( } 667,000 \text { Baht per QALY gained) for patients aged } 20 \text { years to } \\
497,000 \text { Baht per LY saved ( } 7000,000 \text { Baht per QALY gained) for } \\
\text { patients aged } 70 \text { years from a societal perspective. Slightly higher } \\
\text { (i.e., less favorable) cost-effectiveness and cost-utility ratios were } \\
\text { observed with a policy of 'HD first' }\end{array}$ \\
\hline
\end{tabular}

${ }^{*} L Y=$ life years. $Q A L Y=$ quality-adjusted life years

and biases $(67 \%)$. Similarly, cost studies frequently reported study objective and direct medical costs, but none of the cost studies included intangible costs and only a few studies (17\%) included indirect costs. Intangible costs may be difficult to assess well in the context of dialysis due to the lack of a firm value and the challenge in quantifying pain and suffering within a heterogeneous population.

\section{Discussion}

We conducted a systematic search for peer-reviewed economic evaluations of dialysis modalities published between January 2004 and March 2012, with the goal of evaluating the economic literature within the context of recent global dialysis payment policies encouraging greater use of PD, while building on an earlier systematic review of the literature ${ }^{15}$ that was published between 1996 and 2006. The results of our review reiterate that ICHD is generally more costly, and less cost-effective than PD in the majority of studies and countries that examined costs and/or cost effectiveness associated with the different dialysis modalities. These results are consistent with previously published systematic reviews of the literature ${ }^{15,24}$. In fact, there is a growing body of evidence suggesting greater use of PD or the use of PD as first treatment modality for appropriate ESRD patients ${ }^{25-27}$. Our findings show that existing reimbursement incentives for delivering dialysis therapies have implications for both clinical practice and health policy. The burden of rising healthcare costs globally, coupled with competing economic priorities, highlight the importance of establishing policies that encourage the use of PD over ICHD, whenever feasible and clinically appropriate.

There are exceptions where PD has been reported to be more costly than ICHD; these are noted in Table 1. The reasons behind these exceptions are myriad, but chief among them may be methodological differences between studies, as well as variations in practice patterns, cost estimations, and the inclusion/exclusion of specific cost elements. For example, a study conducted in Spain ${ }^{28}$ included staff wages for direct PD-related medical costs, whereas ICHD costs excluded these costs in the calculation of direct medical costs. In effect, this particular study reported PD to be more costly than ICHD.

Most of the studies in our review consider only direct medical and non-medical costs in their analyses. Direct medical costs include physician and other staff costs (fees; salaries); capital costs of hemodialysis machines and PD cyclers; costs associated with establishing and maintaining vascular access; ongoing use of dialysis-related supplies such as solutions, medications, and tubing; as well as costs associated with radiology, laboratory and hospitalization. Direct non-medical costs include overheads for administering and maintaining buildings and facilities but they may also include 
patients' travel to a dialysis center or physician's office. It is important to keep in mind that PD and ICHD rely on very different direct cost components. The direct cost of ICHD is driven primarily by the cost of staff, buildings, infrastructure, and capital equipment (i.e., fixed costs), whereas the direct cost of PD is driven primarily by the supply costs of dialysis solutions, tubing and other disposables (i.e., variable costs). Thus, it is not enough to compare dialysis modalities based on differences in one or two cost components. Rather, cost comparisons of PD and ICHD must be based on the total costs of therapy, as direct medical costs alone do not have the same relevance from all economic perspectives. For instance, in the developing world where labor is relatively inexpensive and the cost of imported dialysis solutions and supplies is high, it is easy to perceive PD as being more expensive than ICHD $^{29}$. The reverse may be true in developed economies where labor is relatively more costly than disposable supplies.

Indirect costs, or productivity losses of patients and caregivers were rarely included in the studies we reviewed, even in the four studies focusing on six countries for which the stated perspective of the analysis was societal ${ }^{30-33}$. Of these, the most comprehensive array of indirect costs is represented in a Thai study that considers all resources used by dialysis patients and/or caregivers, including capital, labor and materials costs of health-care providers, as well as the real and opportunity costs associated with patient treatment time, informal patient care, and sick leave ${ }^{31}$. Of course, the inclusion of indirect and/or productivity costs will substantially increase the reported cost of any dialysis modality, but these costs have a particular impact on the cost of ICHD which requires regular, lengthy, dialysis treatments that are provided outside of patients' homes.

Intangible costs denote those consequences of an intervention that are particularly challenging to measure, such as the value of improved health per se, or the pain, suffering, and impairment in quality of life associated with treatment. Only five $\mathrm{s}^{30,31,34-36}$ of the 24 studies included in our review considered intangible costs, all of them via the utility scores used to arrive at quality-adjusted life years.

Our review has several limitations. First, our review focused on economic evidence comparing PD and HD; articles comparing the clinical and patient outcomes associated with PD and HD were not included in this review. Second, we included all articles we found that compared the costs and/or cost effectiveness of PD vs. ICHD. These articles are of varying quality and our report did not differentiate the quality of these findings. As such, it is difficult to make generalizations about the published literature of dialysis economics owing to the limited number of studies available and differences among them in terms of study methods, geography, scope, and quality. Some studies rely on decades-old data that may not be relevant to present-day economies; other studies fail to indicate the currency-year used in analysis. Between-country differences in economic development, practice patterns, reimbursement structures, provider payment, healthcare system financing, and social norms often make it difficult to interpret the findings from one country in the context of another country. In addition, the proportion of patients on HD vs. PD and the treatment settings (provider demographics such as freestanding/satellite vs. hospital-based dialysis clinics) vary across countries. Even studies that report 'direct costs' may include/exclude different components of direct cost and, thus, may not necessarily produce comparable results. Further, some authors clearly specify the perspective taken in their analyses (e.g., societal, payer, provider); in other papers the perspective is only implied. Reported study methods, too, may be insufficiently transparent to evaluate study quality; for example, the calculations used to derive costs or the elements of costs (e.g., frequency of dialysis, prescription drug use) are often lacking or unclear. Data sources may vary among studies as well; data sources may include disease registries; hospital, insurer, or government databases; secondary literature; government publications; dialysis product distributors; dialysis center data; and/or individual patient interviews. Just one of these between-study differences introduces uncertainty when drawing comparisons among study results. Because published studies of the economics of dialysis often vary on many of these parameters, specific, robust between-study comparisons cannot be made.

Despite the methodological differences and variable quality across the studies within our review, ICHD clearly emerged as a more expensive modality than PD in most of the 19 countries represented in our review. These results are consistent with earlier systematic reviews of the dialysis literature ${ }^{15,37}$. Similarly, the cost-effectiveness studies presented in Table 2 begin to show a nascent picture of costsavings related to $\mathrm{PD}$; the limited number of cost-effectiveness studies and the methodological differences between them (e.g., differences in the variables considered within each modelled analysis) preclude the drawing of specific conclusions.

\section{Conclusion}

The magnitude of costs associated with providing dialysis therapies globally is large and growing. Our findings echo those of prior published reviews and add to the growing body of evidence finding PD is significantly cost-saving compared to ICHD therapy in most developed countries and some developing countries. Additionally, evidence continues to suggest that PD is a cost-effective strategy relative to ICHD. Therefore, it appears that increasing the use of clinically-appropriate PD would substantially reduce healthcare costs and help health systems meet ever-tightening budget constraints.

\section{Author contributions}

FXL and TQ conceived, designed, and implemented the review. JB contributed to the data extraction of the study from reviewed papers and provided expertise in nephrology. FXL, TQ, and GI prepared the first draft of the manuscript. LN contributed to the design and preparation of the manuscript. All authors were involved in reviewing and revising the draft manuscript and have agreed to the final content.

\section{Competing interests}

Frank Xiaoqing Liu is an employee and stockholder of Baxter Healthcare Corporation, Deerfield, IL USA; At the time this research was conducted, Tiffany Quock and Les Noe were employees of ICON, which received research funding from Baxter Healthcare 
Corporation for the systematic review. Tiffany is now at Covance Market Access Services Inc. and Les is now at InVentiv Health Clinical; John Burkart is faculty at Wake Forest University, WinstonSalem, NC, USA and has been an ad hoc consultant for Baxter Healthcare Corporation; Gary Inglese was an employee of Baxter Healthcare Corporation at the time of this manuscript development and is now at Hollister Incorporated.

\section{Grant information}

The study was supported by funding from Baxter Healthcare Corporation, Deerfield, IL 60015 USA. The publication of the study results was not contingent on the sponsor's approval or censorship of the manuscript.

The funders had no role in study design, data collection and analysis, decision to publish, or preparation of the manuscript.

\section{Acknowledgements}

The authors acknowledge Nancy Neil, Ph.D. from Chordata Consulting, LLC and University of Washington, Seattle, WA, USA, for her help on the preparation of the manuscript and Kathryn Webb, MS, for her help on the literature search.
1. Fassett RG, Robertson IK, Mace $R$, et al:: Palliative care in end-stage kidney disease. Nephrology (Carlton). 2011; 16(1): 4-12. PubMed Abstract | Publisher Full Text

2. Jassal SV, Kelman EE, Watson D: Non-dialysis care: an important component of care for elderly individuals with advanced stages of chronic kidney disease. Nephron Clin Pract. 2011; 119(suppl 1): c5-c9. PubMed Abstract | Publisher Full Text

3. Abecassis M, Bartlett ST, Collins AJ, et al.: Kidney transplantation as primary therapy for end-stage renal disease: a National Kidney Foundation/Kidney Disease Outcomes Quality Initiative (NKF/KDOQITM) conference. Clin J Am Soc Nephrol. 2008; 3(2): 471-480.

PubMed Abstract | Publisher Full Text | Free Full Text

4. Renal Resource Center 2010. An Introduction to Peritoneal Dialysis. Reference Source.

5. Ghaffari A, Kalantar-Zadeh K, Lee J, et al.: PD First: Peritoneal Dialysis as the Default Transition to Dialysis Therapy. Semin Dial. 2013; 26(6): 706-713. PubMed Abstract | Publisher Full Text

6. U.S. Renal Data System. USRDS 2012 Annual Data Report: Atlas of Chronic Kidney Disease and End-Stage Renal Disease in the United States. Bethesda, MD: National Institutes of Health, National Institute of Diabetes and Digestive and Kidney Diseases. 2012.

7. Fresenius Medical Care. ESRD Patients in 2011 Reference Source.

8. Zelmer JL: The economic burden of end-stage renal disease in Canada. Kidney Int. 2007; 72(9): 1122-1129.

PubMed Abstract | Publisher Full Tex

9. Praditpornsilpa K, Lekhyananda S, Premasathian N, et al.: Prevalence trend of renal replacement therapy in Thailand: impact of health economics policy. J Med Assoc Thai. 2011; 94(suppl 4): s1-s6. PubMed Abstract

10. Sirivongs DKV, Wangsiripaisal A, et al.: Fact about PD First Policy in Thailand Vol ISBN 978-616-223-129-2. Nonthaburi Thailand: Sahamitrprinting \& publishing. $\mathrm{CO}$, Ltd

11. Rocha MJ, Ferreira S, Martins LS, et al.: Cost analysis of renal replacement therapy by transplant in a system of bundled payment of dialysis. Clin Transplant. 2012; 26(4): 529-531. PubMed Abstract | Publisher Full Text

12. Iglehart JK: Bundled Payment for ESRD - including ESAs in Medicare's Dialysis Package. N Engl J Med. 2011; 364(7): 593-595. PubMed Abstract | Publisher Full Text

13. Golper TA, Guest S, Glickman JD, et al:: Home dialysis in the new USA bundled payment plan: implications and impact. Perit Dial Int. 2011; 31(1): 12-16. PubMed Abstract | Publisher Full Text

14. Council of Australian Governments. National Healthcare Agreement. 2011. Australia. 2011.

Reference Source.

15. Just PM, Riella MC, Tschosik EA, et al:: Economic evaluations of dialysis treatment modalities. Health Policy. 2008; 86(2-3): 163-180.

PubMed Abstract | Publisher Full Text

16. The world bank. how we classify countries. 2013 Reference Source.

17. Moore R, Marriott N: Cost and price in the NHS: the importance of monetary value in the decision-making framework--the case of purchasing renal replacement therapy. Health Serv Manage Res. 1999; 12(1): 1-14. PubMed Abstract

18. Nissenson A, Prichard SS, Cheng IK, et al.: Non-medical factors that impact on ESRD modality selection. Kidney Int Suppl. 1993; 40: s120-127. PubMed Abstract

19. Little J, Irwin A, Marshall T, et al.: Predicting a patient's choice of dialysis modality: experience in a United Kingdom renal department. Am J Kidney Dis. 2001; 37(5): 981-986.

PubMed Abstract | Publisher Full Text

20. Wordsworth $S$, Ludbrook A: Comparing costing results in across country economic evaluations: the use of technology specific purchasing powe parities. Health Econ. 2005; 14(1): 93-99.

PublMed Abstract | Publisher Full Text

21. Hallinen T, Soini EJ, Martikainen JA, et al:: Costs and quality of life effects of the first year of renal replacement therapy in one finnish treatment centre. $J$ Med Econ. 2009; 12(2): 136-140.

PubMed Abstract | Publisher Full Text

22. Fukuhara S, Yamazaki C, Hayashino $\mathrm{Y}$, et al:: The organization and financing of end-stage renal disease treatment in Japan. Int $J$ Health Care Finance Econ. 2007; 7(2-3): 217-231.

PubMed Abstract | Publisher Full Text

23. Ofman JJ, Sullivan SD, Neumann PJ, et al: Examining the value and quality of health economic analyses: implications of utilizing the QHES. J Manag Care Pharm. 2003; 9(1): 53-61. PubMed Abstract

24. MacLeod A, Grant A, Donaldson C, et al.: Effectiveness and efficiency of methods of dialysis therapy for end-stage renal disease: systematic reviews. Health Technol Assess. 1998; 2(5): 1-166.

PubMed Abstract | Publisher Full Text

25. Burkart $\mathrm{J}$ : The future of peritoneal dialysis in the united states: optimizing its use. Clin J Am Soc Nephrol. 2009; 4(suppl 1): s125-131. PubMed Abstract | Publisher Full Text

26. Chaudhary K, Sangha H, Khanna R: Peritoneal dialysis first: rationale. Clin J Am Soc Nephrol. 2011; 6(2): 447-456. PubMed Abstract | Publisher Full Text

27. Jose MD, Johnson DW, Mudge DW, et al.: Peritoneal dialysis practice in Australia and New Zealand: a call to action. Nephrology (Carlton). 2011; 16(1): $19-29$.

PubMed Abstract | Publisher Full Text

28. Lamas Barreiro J, Alonso Suarez M, Saavedra Alonso JA, et al: Costs and added value of haemodialysis and peritoneal dialysis outsourcing agreements. Nefrologia. 2011; 31(6): 656-663. PubMed Abstract | Publisher Full Text

29. Chugh KS, Jha V, Chugh S: Economics of dialysis and renal transplantation in the developing world. Transplant Proc. 1999; 31(8): 3275-3277. PubMed Abstract | Publisher Full Text

30. Kontodimopoulos N, Niakas D: A socio-economic comparison of hemodialysis and peritoneal dialysis in greece. Int $\mathrm{J}$ Healthcare Technology and Management. 2005; 6(3): 296-306. Publisher Full Text

31. Teerawattananon $\mathrm{Y}$, Mugford M, Tangcharoensathien V: Economic evaluation of palliative management versus peritoneal dialysis and hemodialysis for end-stage renal disease: evidence for coverage decisions in Thailand. Value 
Health. 2007; 10(1): 61-72.

PubMed Abstract | Publisher Full Text

32. Neil N, Walker DR, Sesso R, et al.: Gaining efficiencies: resources and demand for dialysis around the globe. Value Health. 2009; 12(1): 73-79.

PubMed Abstract | Publisher Full Text

33. Pacheco A, Saffie A, Torres R, et al.: Cost/Utility study of peritoneal dialysis and hemodialysis in Chile. Perit Dial Int. 2007; 27(3): 359-363. PubMed Abstract

34. Haller M, Gutjahr G, Kramar R, et al.: Cost-effectiveness analysis of renal replacement therapy in Austria. Nephrol Dial Transplant. 2011; 26(9): 2988-2995. PubMed Abstract | Publisher Full Text

35. Howard K, Salkeld G, White S, et al.: The cost-effectiveness of increasing kidney transplantation and home-based dialysis. Nephrology (Carlton). 2009; 14(1): 123-132.

PubMed Abstract | Publisher Full Text

36. Kontodimopoulos N, Niakas D: An estimate of lifelong costs and QALYs in rena replacement therapy based on patients' life expectancy. Health Policy. 2008; 86(1): 85-96.

PubMed Abstract | Publisher Full Text

37. Menzin J, Lines LM, Weiner DE, et al:: A review of the costs and cost effectiveness of interventions in chronic kidney disease: implications for policy. Pharmacoeconomics. 2011; 29(10): 839-861.

PubMed Abstract | Publisher Full Text

38. Benain JP, Faller B, Briat C, et al.: [Cost of dialysis in France]. Nephrol Ther 2007; 3(3): 96-106.

PubMed Abstract | Publisher Full Text

39. Durand-zaleski I, Combe C, Lang P: International Study of Health Care Organization and Financing for end-stage renal disease in France. Int $J$ Health Care Finance Econ. 2007; 7(2-3): 171-183.

PubMed Abstract | Publisher Full Text

40. Pontoriero G, Pozzoni P, Vecchio LD, et al:: International study of health care organization and financing for renal replacement therapy in Italy: an evolving reality. Int J Health Care Finance Econ. 2007; 7(2-3): 201-215.

PubMed Abstract | Publisher Full Text

41. Ashton T, Marshall MR: The organization and financing of dialysis and kidney transplantation services in New Zealand. Int J Health Care Finance Econ. 2007; 7(4): 233-252.

PubMed Abstract | Publisher Full Text
42.

Villa G, Rodriguez-carmona A, Fernandez-ortiz I, et al.: Cost analysis of the Spanish renal replacement therapy programme. Nephrol Dial Transplant. 2011; 26(11): 3709-3714.

PubMed Abstract | Publisher Full Text

43. Sandoz MS, Ess SM, Keusch GW, et al.: Prevalence and direct medical costs of end-stage renal disease in patients with type 2 diabetes mellitus in Switzerland for 2001. Swiss Med Wkly. 2004; 134(31-32): 448-458. PubMed Abstract

44. Baboolal K, McEwan $\mathrm{P}$, Sondhi $\mathrm{S}$, et al.: The cost of renal dialysis in a UK setting--a multicentre study. Nephrol Dial Transplant. 2008; 23(6): 1982-1989.

PubMed Abstract | Publisher Full Text

45. Berger A, Edelsberg J, Lnglese GW, et al:: Cost comparison of peritoneal dialysis versus hemodialysis in end-stage renal disease. Am J Manag Care. 2009; 15(8): 509-518. PubMed Abstract

46. Neil N, Guest S, Wong L, et al.: The financial implications for Medicare of greater use of peritoneal dialysis. Clin Ther. 2009; 31(4): 880-888. PubMed Abstract | Publisher Full Tex

47. Shih YC, Guo A, Just PM, et al:: Impact of initial dialysis modality and modality switches on Medicare expenditures of end-stage renal disease patients. Kidney Int. 2005; 68(1): 319-329.

PubMed Abstract | Publisher Full Text

48. Jeloka TK, Upase S, Chitikeshi S, et al.: Monthly cost of three exchanges a day peritoneal dialysis is same as of thrice a week hemodialysis in self-paying Indian patients. Indian J Nephrol. 2012; 22(1): 39-41.

PubMed Abstract | Publisher Full Text | Free Full Text

49. Erek E, Sever MS, Akoglu E, et al:: Cost of renal replacement therapy in Turkey. Nephrology (Carlton). 2004; 9(1): 33-38. PubMed Abstract | Publisher Full Text

50. Salonen $\mathrm{T}$, Reina $\mathrm{T}$, Oksa $\mathrm{H}$, et al.: Alternative strategies to evaluate the costeffectiveness of peritoneal dialysis and hemodialysis. Int Urol Nephrol. 2007; 39(1): 289-298.

PubMed Abstract | Publisher Full Text

51. Hooi IS, Lim TO, Goh A, et al:: Economic evaluation of centre haemodialysis and continuous ambulatory peritoneal dialysis in Ministry of Health hospitals, Malaysia. Nephrology (Carlton). 2005; 10(1): 25-32.

PubMed Abstract | Publisher Full Text 


\title{
Open Peer Review
}

\section{Current Peer Review Status:}

\section{Version 1}

Reviewer Report 25 June 2014

https://doi.org/10.5256/f1000research.3142.r5023

(c) 2014 Nissenson A. This is an open access peer review report distributed under the terms of the Creative Commons Attribution License, which permits unrestricted use, distribution, and reproduction in any medium, provided the original work is properly cited.

\author{
Allen R. Nissenson \\ DaVita Inc., El Segundo, CA, USA
}

This paper is a systematic review of the comparative cost of dialysis modalities. In some ways it is a self-fulfilling prophecy- led by Baxter, clearly with a strong proprietary interest in seeing expansion of peritoneal dialysis. Having said that, however, the authors do a reasonable job of articulating the limitations of the current analysis. There are a number of issues, however, that need to be addressed for the conclusions to be supportable:

1. The authors need to more clearly distinguish between "cost" and "payment". Although this is complex and may be difficult with the papers that were available for analysis, this is key if the purpose is to inform policy makers or clinicians in various countries about the relative value provided by ICHD vs. PD. For example, despite being "less costly" than ICHD, PD may not be viable in a country where the actual payment is less than the actual cost of delivering the modality.

2. It is not clear how the comparison of total costs is accounted for vs. the costs of the modality per se. It would be much more useful to provide information on the distribution of costs by category and how these differ by modality and country. At the end of the day it is the total costs of care that matter- one might envision a country where there is little payment for in-patient care. Any differences in hospitalization rates might not be reflected in the data presented but may be important in determining which modality is most cost effective.

3. In addition to the comment above, the authors very glibly state that clinical outcomes for ICHD and PD are the same. This may not be the same in all countries, however. For example, if peritonitis rates are high and hospitalizations are frequent for infection or catheter malfunctions the total costs of PD may be significantly higher than ICHD.

4. The paragraph in the Introduction about the changing reimbursement systems is too simplistic and rapidly becoming outdated. The authors need to contextualize this work by clearly discussing the need to examine total costs of care and the overall value of competing modalities (quality/cost). 
5. The tables would be easier to interpret if the currency were normalized. I understand the complexity of this, but just showing the comparison between ICHD and PD within a country and not among countries seems to be a missed opportunity.

Competing Interests: No competing interests were disclosed.

\section{I confirm that I have read this submission and believe that I have an appropriate level of expertise to confirm that it is of an acceptable scientific standard, however I have significant reservations, as outlined above.}

Reviewer Report 07 February 2014

https://doi.org/10.5256/f1000research.3142.r2781

(C) 2014 Klarenbach S. This is an open access peer review report distributed under the terms of the Creative Commons Attribution License, which permits unrestricted use, distribution, and reproduction in any medium, provided the original work is properly cited.

\section{Scott Klarenbach}

Division of Nephrology, University of Alberta, Alberta, Canada

The authors have conducted a systematic review of the cost of provision of peritoneal dialysis versus hemodialysis. They have considered a more recent era than previous reviews, evaluating studies published between 2004 and 2012. Using a well described search strategy and inclusion and exclusion criteria, they provided a narrative review of the 24 cost and cost-effectiveness studies. In tabular format they provided a brief description of each study, and for costing studies provided a ratio of the costs of hemodialysis versus PD. The results of each country were categorized by national income status.

The results of the 24 studies are congruent with previous reviews suggesting that compared to in center hemodialysis, peritoneal dialysis is less costly to provide. The limitations of the studies including differences in perspective, cost categories, and quality are well described. This is a generally well-written and well conducted study and is an important addition to the literature as healthcare systems strive for economic sustainability.

There is a conflict of interest as Baxter is a major supplier of PD equipment and supplies, and many of the author are or were employees / stockholders. This however is clearly outlined in the competing interests section. There does not appear to be any major discernible bias imparted by this.

I have some suggestions to improve clarity and organization of the paper:

\section{Major comments}

In several places including the abstract and final conclusion it is stated that increase in the use of clinically appropriate PD would reduce healthcare costs. More precise language should be used to indicate that PD should be used instead of hemodialysis (technical 
efficiency). This is simply to highlight the fact that some health care systems may not provide dialysis therapy at all, or provide dialysis for only a small proportion of the population. This analysis does not compare the cost cost-effectiveness of PD versus conservative management. It might be prudent to make this explicit at some point in the paper, perhaps the discussion.

There are several sentences or paragraphs in the results section which I think would be better suited to the methods section. First is the discussion of how income status of each of the countries included in the review were determined. This is in the first paragraph of the results section. The first paragraph of column 2 on page 4 discusses how the ratio of HD to PD costs are determined and I would suggest they should also be in the method section.

There are also several sections in the results paragraphs that are more of an interpretation of the results than simply stating the results of their systematic review. For example page 4 first column third paragraph describe the challenges of cross-country comparison but these first few sentences do not describe any results. This would be better suited to the discussion section. I would suggest that the authors go through the results section and move interpretive statements to the discussion. Further, statements around limitations would also be better suited to the discussion.

While I agree with the conclusion that increasing the proportion of patients treated with dialysis therapy to PD would lower health care costs, the feasible proportion of patients suitable for peritoneal analysis is controversial. However it is clear that at least in several jurisdictions such as Canada and United States, there are segments of the patient population that would not be suitable for PD, recognizing that PD is generally thought to be significantly underutilized. Exploration of this in the discussion would be useful to place the results in context.

\section{Other comments}

Page 3 column 2 methods section: The prior literature synthesis from 1996 to 2006 should be referenced.

Page 7 column 1 discusses "reimbursement incentives". Reimbursement implies payment for delivery of a service versus actual cost. These are two different concepts. As this article is looking at cost rather than the effect of reimbursement practices or incentives, I would suggest that this terminology be removed.

A recent paper has been published that attempts to look at reasons why PD costs may be higher in some low or middle income countries. This paper suggested that lack of local manufacturing of PD supplies, a low number of PD patients, and high import tariffs may make PD less attractive compared to hemodialysis. It may be worthwhile to incorporate this into the discussion (Karopadi et al., 2013).

Competing Interests: No competing interests were disclosed.

I confirm that I have read this submission and believe that I have an appropriate level of expertise to confirm that it is of an acceptable scientific standard. 
The benefits of publishing with F1000Research:

- Your article is published within days, with no editorial bias

- You can publish traditional articles, null/negative results, case reports, data notes and more

- The peer review process is transparent and collaborative

- Your article is indexed in PubMed after passing peer review

- Dedicated customer support at every stage

For pre-submission enquiries, contact research@f1000.com 